\title{
Effects of Network Infrastructure sharing Challenges on Open Information Communication Technology Infrastructure Sharing among Mobile Service Providers in Kenya
}

\author{
Peter Namisiko, Dr. Maurice Sakwa and Prof. Mwangi Waweru \\ College of Human Resources and Development, Jomo Kenyatta University of Agriculture and Technology, Nairobi, \\ +254 , Kenya \\ Email: namsiko@gmail.com, sakwa98@yahoo.com,waweru_mwangi@icsit.jkuat.ac.ke
}

\begin{abstract}
The study sought to investigate the effects of network infrastructure challenges on open ICT infrastructure sharing by Mobile Service Providers in Kenya. Specifically, the study investigated network sharing challenges as the main determinants to open ICT infrastructure sharing by Mobile Service Providers in Kenya. The empirical literature revealed that Open ICT Infrastructure sharing can substantially reduce capital and operational expenditure thereby increasing the speed of network rollouts, improve coverage and help meet the capacity demands of increased data traffic. Other reviews revealed that each sharing environment is different and may have pressures and priorities that change throughout the process of establishing a partnership between two operators with a view to developing a framework for Open ICT infrastructure sharing. Data was collected from employees from Safaricom, Airtel and Orange in order to study the population. A target population of 800 employees from the three Mobile Service Providers in Kenya was considered. Both Stratified and purposive sampling techniques were used to identify the respondents. A sample size of 86 respondents was used in this study using both structured questionnaires and scheduled interviews. Both descriptive and inferential statistics were used to analyse data collected from respondents in this study. Network service control and Coverage, Network growth and Experience and Resources were identified as the main challenges facing Network sharing by Mobile Service Providers. It is hoped that the results obtained from this study will be beneficial to stakeholders in Mobile Service industry formulate policies that promote ICT Infrastructure sharing with a view to promoting universal access and saving on expenditures.
\end{abstract}

Index Terms - Network sharing, Open ICT infrastructure sharing, Mobile Service Providers, Challenges.

\section{INTRODUCTION}

Open Information Communication Technology Infrastructure sharing is the joint use of network facilities by two or more operators subject to agreement specifying relevant technical and commercial conditions [1]. The main reason for ICT infrastructure sharing in mobile service industries in the countries that have implemented has been to cut down expenditure and reduce the need to build new masts on which to locate their equipment [2].The term Information Communication Technology Infrastructure sharing incorporates Site sharing, Network sharing and Spectrum sharing [3].

The term Network sharing may be defined as to sharing network assets that are considered to be an active part of providing operator services, such as antennas, radio base stations and, in some cases, spectrum. This form of sharing may allow Mobile Service Providers to differentiate themselves by providing value added services in addition to the standard telecom services such as PSTN (Public Switched Telephone Networks), and GSM (Global System for Mobile Communication) services on mobile phones. In the United Kingdom, Orange and Vodafone announced plans in August 2007 to share their Radio Access Network (RAN) across the entire country [4]. This was after realization that around two thirds of all mobile phone Base Stations in use in the UK were located on existing buildings and structures, including buildings, TV and radio transmission towers and existing mobile phone masts. By sharing existing structures, the two mobile network operators aimed to reduce the need to build new masts on which to locate their equipment [5]. The driving force behind Network sharing in UK was competitive nature of UK market that led to declining revenues and margins and the stringent coverage requirements imposed by regulators thereby, forcing the Mobile Service Providers to embrace Open ICT infrastructure sharing as the only alternative to cost savings. However, Asset Management and Valuation was identified as a major challenge in network sharing [6]. To mitigate this challenge, Orange and Vodafone created a joint team known as Cornerstone to facilitate sharing of their combined UK masts. Since then, Cornerstone has been deploying new masts and consolidating the existing networks on behalf of the two mobile network operators. Another challenge faced was cultural alignment and stakeholder management of both Orange and Vodafone 
[7]. The cultural mindsets of both companies stifled the successful completion of the joint venture. In the $\mathrm{T}$ Mobile and 3 in the UK, the joint executive team gave a clear vision and direction to all the parties involved with full endorsement of the joint venture's role thereby leading to the conclusion of Network sharing agreement between T-Mobile and 3 [5].

In Kenya, each Mobile Service Provider is expected to build or lease the infrastructure it requires, although the license they own allows them to share their infrastructure on commercial arrangements [8]. The Government through CCK has not formulated the rules for ICT infrastructure sharing. As a result of this, few agreements have successfully been reached in terms of ICT infrastructure sharing. Only Safaricom Co. Ltd and Telkom Kenya Ltd have partially allowed for ICT infrastructure sharing in only few regions of the country under written agreements [9].

Given this background, it is imperative to assess the effects of network infrastructure challenges on Open ICT infrastructure sharing by Mobile service Providers in Kenya. Open ICT infrastructure sharing can substantially reduce capital and operational expenditure thereby increasing the speed of network rollouts, improve coverage and help meet the capacity demands of increased data traffic [5]. This approach can promote Universal access that Government of Kenya is trying to achieve [10]. The penetration of masts in rural areas is increasing at an exponential rate. The construction of towers is mushrooming and in near future towers population across the country will change urban and rural landscape [9]. The present individualism is reflecting under utilization of BTS (Base Transceiver Station) sites and resources and is also a burden on the operators. According to [6], there is also general public concern over effects on health and environment due to growing numbers of Base stations in cities towns and rural areas. This is a concern to most Mobile Service Providers in Kenya. This study seeks to assess these challenges that are making Open ICT Infrastructure sharing remain a mirage despite the enormous benefits that come with Open ICT infrastructure sharing. In light of the findings, the study intends to determine a framework for Open ICT Infrastructure sharing for use by Mobile Service Providers in Kenya.

Despite the Mobile Service Providers interest in Open ICT infrastructure sharing, little attention is being paid to conclusion of deals that leads to Infrastructure sharing [9]. So, why are Mobile Service Providers reluctant to embrace Open ICT infrastructure sharing in Kenya?

The main purpose of this study was to investigate the effects of network infrastructure challenges on Open ICT Infrastructure sharing by Mobile Service Providers in Kenya. Specifically, the study intends to assess the effects of network sharing challenges on Open ICT infrastructure sharing by Mobile Service Providers in Kenya.

The rest of the paper is organized into three parts. First, a literature review related Network sharing challenges on Open ICT infrastructure sharing by Mobile Service
Providers is presented. Next, research methodology is presented and research findings from the survey. Conclusion is then made regarding the findings. It is hoped that the results obtained from this study will be beneficial to stakeholders in Mobile Service industry formulate policies that promote ICT Infrastructure sharing with a view to promoting universal access and saving on expenditures.

\section{LITERATURE REVIEW}

\section{A. Theoretical and Conceptual Framework}

This study is based on Resource Based View theory and Cooperative Game theory. The Resource Based View theory is important in this study because Open ICT infrastructure sharing by Mobile Service Provides includes the sharing of sites, network and spectrum which form a capital resource [11]. This theory examines the relation between a firm's internal characteristics and performance [12]. It bases its assumption on strategic resources that are heterogeneously distributed across the firms and this distribution is stable over time (immobile). In this study the strategic resources will be sites, spectrum and network that can be sources of sustained competitive advantage for a firm. On the other hand, Cooperative Game theory is the study of strategic decision making process. This is compared to a game where groups of players or coalitions may enforce cooperative behaviour; hence the game is a competition between coalitions of players, rather than between individual players [13]. According to this theory players choose the strategies by a consensus decision making process. This theory is important in this study since the issue of infrastructure sharing among Mobile Service Providers can be modelled as Cooperating games.

Based on the theoretical framework, the following conceptual framework was derived.

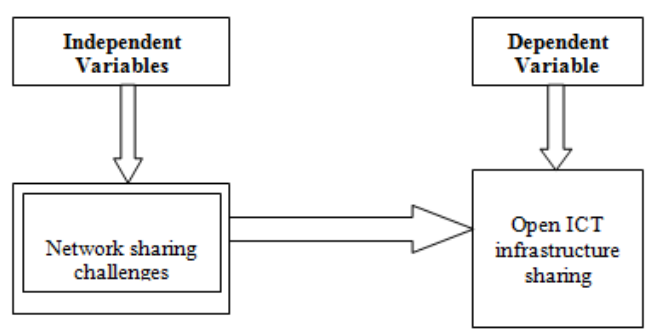

Fig. 1. Conceptual Framework

Source: Researchers own

\section{B. Review of Related Literature}

ICT Infrastructure sharing can be defined as the joint use of network facilities by two or more Mobile Service Providers subject to agreement specifying relevant technical and commercial conditions [1]. The network facilities can be masts, Base Transceiver Stations (BTS), Spectrum, and other facilities. Sharing of Telecommunication ICT Infrastructure among Mobile Service Providers is becoming a requirement and process 
of business in the Mobile Service Industry where competitors are becoming partners in order to lower their increasing investments [14]. According to [5], ICT Infrastructure incorporates site sharing, network sharing and spectrum sharing. In Node B Sharing, Radio network controller (RNC) and Core Network are not shared in this model, so that each service provider can maintain control of their equipment and spectrum use [4]. According to [19], the separation of the Core Networks also allows each service provider to offer differentiated services to their subscribers. In Back Haul sharing, Core network elements such as switching centres, GPRS service nodes, transmission equipment and all links connecting elements of the core network are shared [15]. Back haul sharing can be of great use in provision of Mobile Services in rural and remote areas.

Network sharing may be defined as to sharing network assets that are considered to be an active part of providing operator services, such as antennas, radio base stations and, in some cases, spectrum (Sony Ericsson, 2010, p. 11). Network sharing may also incorporate sharing the intelligence network (Chatzicharistou, 2010). Intelligent network is the standard network architecture intended for fixed as well as mobile telecom networks. It allows operators to differentiate themselves by providing valueadded services in addition to the standard telecom services such as PSTN, ISDN and GSM services on mobile phones. Active network components that support intelligent networks include base stations, antennas and transmission links. The definition of network sharing adopted in this study will based on Chatzicharistou [15] that views spectrum sharing as being independent of network sharing hence the description of network sharing will focus on tangible components. A more profound definition will be based on PTA [16, p. 12] that defines network sharing as the sharing of antenna, feeder cables, node $\mathrm{B}$, and transmission equipment. This definition will leave out spectrum sharing. Based on this definition, network sharing can be categorized in three categories namely: sharing radio access network, node B sharing and backhaul sharing. Radio Access Network (RAN) is where antenna, feeder cable and transmission equipment is shared [17]. This can be shown in the figure below:

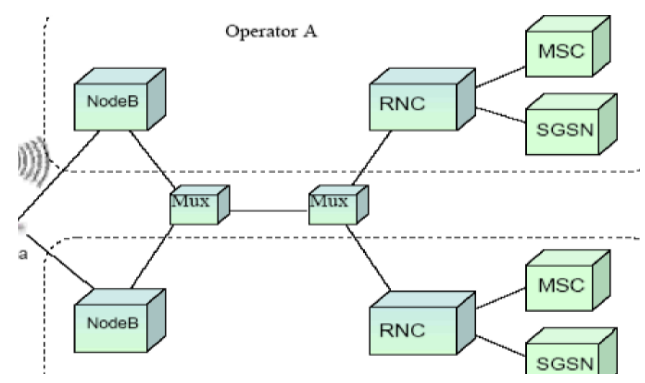

Fig.2. RAN site sharing

Source: [18]

ICT infrastructure sharing is a highly country specific issue that is possible to differ from country to country mainly because of differences in the legal framework, the physical environment, the already built infrastructure, the market conditions or other factors [15]. The Challenges of implementing Open ICT Infrastructure sharing by Mobile Service Providers may vary from one country to another depending on legal framework, physical environment, already built infrastructure, market conditions and other factors. According to [20], the challenges facing Network sharing include Network service control and Coverage, Network growth, Experience and Resources and Market Dynamics. These challenges are explained in a section that follows in detail.

\section{Network Service Control and Coverage}

Determining geographic regions and population coverage areas plays a big part in where operators should compete and where they can collaboratively share in order to better compete with others [20]. The basic assumption in this approach is that Network sharing does not have to be applied uniformly across the whole network environment. For instance, major cities may be too sensitive to be shared when considering the balance between benefit and potential loss of market position, whereas a dedicated network in rural areas may not provide any competitive advantage and is often a prime candidate for full active sharing, potentially across multiple operators [19]. Despite all the best intentions, some Mobile Service Providers may be disadvantaged through a network sharing program. This impact needs to be understood and managed so that it does not become an impediment to Network sharing. [1], points out that a shared network environment will evolve, be managed and funded beyond the initial shared environment. For instance, In Australia, Telstra and 3 created a shared 3G network where one operator leveraged the immediate availability of the other's infrastructure but, beyond that initial advantage, they were not locked into sharing the costs of future expansion [20].

\section{Programme Complexity and Risk}

Network sharing may be complex, slippages and scope changes in the programme are likely to increase costs substantially. Key elements need to be assessed early and risks mitigated within the program design. These include the creation of a target reference network plan, network architecture and design criteria, transmission strategy, landlord negotiation, lease termination costs and capacity of existing sites to be shared, including planning permission [17]. Based on this argument, the IT systems needed to manage shared operations should be established before the sharing starts and work transparently across both organizations. If the Mobile Service Providers do not put this mechanisms in place, then Network sharing may not be successful. Network sharing has in some cases been particularly difficult to implement. For instance, in one case two operators abandoned their plans to share a $3 \mathrm{G}$ network when the benefits simply did not justify the complexity required to make it happen [15]. Complex sharing solutions tend to increase management costs, so it is important to agree upfront the success criteria by which the program will be measured. The Mobile Service Providers also need to 
agree on the budgets that are jointly allocated for undertaking the network sharing programme and how to secure an equitable investment and return from such a venture.

\section{Experience and Resources}

Network sharing is a complex and unique undertaking, particularly if consolidation of existing coverage takes place. Large scale network consolidation is very different from a roll-out program, and requires additional resources and skills that do not typically already exist in an operator's organization [14]. Access to these resources and expertise must be a major consideration in developing any execution plan because relearning the experiences of others can be very costly. If the Mobile Service Operators lack the necessary experience and resources, then Network sharing may not take place. This was successfully executed and agreed in advance of the MBNL shared network program with the early involvement of key suppliers.

In summary, Open ICT Infrastructure sharing can substantially reduce capital and operational expenditure thereby increasing the speed of network rollouts, improve coverage and help meet the capacity demands of increased data traffic [1]. European operators have been the most active in sharing networks [5]. The reasons for this include the competitive nature of European markets forcing declining revenues and margins and the stringent coverage requirements imposed by regulators. This has resulted in European operators being more willing to set aside competitive concerns and instead focus on the costsaving possibilities of network sharing. In developing markets such as India, the sheer size and low revenue segments of some areas make it financially impossible for smaller operators to achieve coverage through their own proprietary networks [5].

Each sharing environment is different and may have pressures and priorities that change throughout the process of establishing a partnership between two operators. In Kenya, there is no policy advanced by CCK that addresses open ICT infrastructure sharing, although the Mobile Service can agree on their own volition to share some components of the their network [21]. Despite various studies conducted in various countries such as Europe and India, there is no conclusive study that has been conducted in Kenya to ascertain the main challenges facing Open ICT Infrastructure sharing by Mobile Service Providers from available literature. This is the research gap that this study intends to fill.

\section{Methodology}

The study adopted a survey design involving the use of questionnaires and interviews to collect data on a wide range of variables at a given point in time. Data was collected from employees from Safaricom, Airtel and Orange to study the population. A target population of 800 expert employees from the three Mobile Service Providers in Kenya was considered [22]. These are employees that have acquired knowledge, skills and experience in the ICT industry. These employees included engineers, system administrators, technicians and IT Experts. The researcher believed that these set of employees have the necessary skills, knowledge and experience to identify effects of infrastructure challenges on Open ICT infrastructure sharing in the Mobile Service industry. In arriving at this population, the researcher relied upon data collected by Kenya National Bureau of Statistics that gives employment levels as indicated in the table below:

Table 1. Number of Expert Employees in three Mobile Service Providers in Kenya

\begin{tabular}{cc}
\hline Name of Mobile Service Provider & Number of Employees \\
\hline Safaricom & 400 \\
Airtel & 167 \\
Orange & 233 \\
Total & 800 \\
\hline
\end{tabular}

Source: [22]

The study was conducted in three Mobile Service Providers in Kenya namely; Safaricom, Orange and Airtel in their headquarters which is based in Nairobi.

Stratified sampling technique was used to identify the respondents. A sample size of 86 respondents was used in this study.

Table 2. Table showing Sampling Criteria for Safaricom

\begin{tabular}{ll}
\hline Number of Expert Employees & Number of Respondents \\
\hline 400 & 43 \\
\hline
\end{tabular}

Source: Researchers own

Table 3. Table showing Sampling Criteria for Airtel

\begin{tabular}{ll}
\hline Number of Expert Employees & Number of Respondents \\
\hline 167 & 18 \\
\hline
\end{tabular}

Source: Researchers own

Table 4. Table showing Sampling Criteria for Orange

\begin{tabular}{ll}
\hline Number of Expert Employees & Number of Respondents \\
\hline 233 & 25 \\
\hline
\end{tabular}

Source: Researchers own

Both structured questionnaires and scheduled interviews will be used in data collection.

A pilot study was undertaken on at least 10 respondents to test the reliability and validity of the questionnaire. The rule of thumb is that $1 \%$ of the sample should constitute the pilot test [23]. The proposed pilot test was within the recommendation.

The researcher used the most common internal consistency measure known as Cronbach's alpha $(\alpha)$. It indicates the extent to which a set of test items can be treated as measuring a single latent variable [24]. The recommended value of 0.7 was used as a cut-off of reliabilities.

Both descriptive and inferential statistics were used to 
analyse data collected from respondents in this study. Chi-square test was used to test the following hypotheses which are based on the Objectives of the study:

H0: There exists no relationship between networks sharing in each of the three Mobile Service Providers in Kenya.

Data from open ended questionnaires and interviews was grouped under broad themes and converted into frequency counts. All data was analysed at level significance of $95 \%$ or $\alpha=0.05$ and the degrees of freedom depending on the particular case as was determined. This value $(\alpha=0.05)$ was chosen because the sample size has been adopted from figures calculated on the basis of 0.95 level of confidence. The study used SPSS software package to analyse the data collected.

\section{Research Findings and Discussions}

From the data collected, out of the 86 questionnaires administered, 71 questionnaires were filled and returned, which represents $82.6 \%$ response rate. This response rate is considered satisfactory to make conclusions for the study. Reliability of the constructs is shown below in table 5 .

Table 5. Reliability test of constructs

\begin{tabular}{lclll}
\hline Infrastructure Challenges & $\begin{array}{l}\text { Reliability } \\
\text { Alpha }\end{array}$ & Cronbach's & Comments \\
\hline $\begin{array}{l}\text { Network } \\
\text { challenges }\end{array}$ & sharing & 0.903 & Accepted \\
\hline
\end{tabular}

The specific objective of this study was to assess the effects of network sharing challenges on Open ICT infrastructure sharing by Mobile Service Providers in Kenya. This study identified the following components of network sharing that can be shared by Mobile Service Providers: Antennae, Feeder cables, Node B and Transmission equipment.

Table 6. Descriptive statistics of the network sharing components

\begin{tabular}{|c|c|c|c|c|c|}
\hline \multicolumn{5}{|l|}{ Antennae } & \multirow[b]{2}{*}{ Total } \\
\hline & $\begin{array}{l}\text { Strongly } \\
\text { Agree }\end{array}$ & Agree & $\begin{array}{l}\text { Undecide } \\
\mathrm{d}\end{array}$ & $\begin{array}{l}\text { Disagre } \\
\mathrm{e}\end{array}$ & \\
\hline $\begin{array}{l}\text { Safarico } \\
\mathrm{m}\end{array}$ & 1 & 6 & 13 & 12 & 39 \\
\hline Airtel & 1 & 3 & 9 & 4 & 17 \\
\hline Orange & 0 & 1 & 7 & 3 & 15 \\
\hline Total & 2 & 10 & 29 & 19 & 71 \\
\hline \multicolumn{6}{|c|}{ Feeder Cables } \\
\hline $\begin{array}{l}\text { Safarico } \\
\mathrm{m}\end{array}$ & 2 & 14 & 14 & 9 & 39 \\
\hline Airtel & 1 & 9 & 4 & 3 & 17 \\
\hline Orange & 0 & 12 & 3 & 0 & 15 \\
\hline $\begin{array}{l}\text { Total } \\
\text { Node B }\end{array}$ & 3 & 35 & 21 & 12 & 71 \\
\hline $\begin{array}{l}\text { Safarico } \\
\mathrm{m}\end{array}$ & 0 & 11 & 20 & 8 & 39 \\
\hline Airtel & 1 & 8 & 3 & 5 & 17 \\
\hline Orange & 0 & 3 & 12 & 0 & 15 \\
\hline Total & 1 & 22 & 35 & 13 & 71 \\
\hline \multicolumn{6}{|c|}{ Transmission Equipment } \\
\hline $\begin{array}{l}\text { Safarico } \\
\mathrm{m}\end{array}$ & 0 & 2 & 20 & 17 & 39 \\
\hline Airtel & 0 & 0 & 3 & 14 & 17 \\
\hline Orange & 1 & 0 & 0 & 14 & 15 \\
\hline Total & 1 & 2 & 23 & 45 & 71 \\
\hline
\end{tabular}

\section{Source: Research Data}

From the table, only 7 out of 39 respondents from Safaricom (18\%), only 4 out of 17 respondents from Airtel $(24 \%)$ and only 1 out of 15 respondents from Orange $(7 \%)$ agreed that antennas could be shared in an open ICT infrastructure sharing framework.

This findings reinforce a similar study that was conducted by [4] who noted that the core network elements of which antenna is part of should not be shared, so that each service provider can maintain control their equipment. 16 out of 39 respondents from Safaricom (41\%), 10 out of 17 respondents from Airtel (59\%) and 12 out of 15 respondents from Orange $(80 \%)$ agreed that feeder cables could be shared in an open ICT infrastructure sharing framework.

Based on these findings, a slight majority of the respondents felt that feeder cables could easily be shared. This is because these respondents felt that could only be used for distribution of signals which can not pose a major threat in terms of sharing infrastructure. With regards to Node B, only 11 out of 39 respondents from Safaricom (28\%), 9 out of 17 respondents from Airtel (53\%) and only 3 out of 15 respondents from Orange (20\%) agreed that Node B could be shared in an open ICT infrastructure sharing framework. This findings relate to similar findings by [5], [15] and [25] who postulated that intelligent network components of which Node B is part of in a standard network architecture intended for fixed as well as mobile telecommunication networks should allow Mobile Service Providers to differentiate themselves by providing value added services in addition to the standard telecom services such as PSTN, ISDN and GSM services on mobile phones and as such should not be shared. Only 2 out of 39 respondents from Safaricom (5\%), none out of 17 respondents from Airtel $(0 \%)$ and only 1 out of 15 respondents from Orange $(7 \%)$ agreed that transmission equipment could be shared in an open ICT infrastructure sharing framework. This findings relate to similar findings by [5], [15] and [25] who postulated that intelligent network components of which the transmission equipment is part of in a standard network architecture intended for fixed as well as mobile telecommunication networks should allow Mobile Service Providers to differentiate themselves by providing value added services in addition to the standard telecom services such as PSTN, ISDN and GSM services on mobile phones and as such should not be shared.

\section{Network Service Coverage}

In the survey, the respondents were asked to indicate whether they thought Network Service Coverage had an impact on realization of Open ICT infrastructure sharing with respect to Antennae, Feeder cables, Node B and Transmission equipment. The table below illustrates the findings: 
Table 7. Network Service Coverage

\begin{tabular}{|c|c|c|c|c|}
\hline & \multicolumn{3}{|c|}{ Network Service Control and Antenna } & \multirow[t]{2}{*}{ Total } \\
\hline & Yes & No & Not Sure & \\
\hline Safaricom & 6 & 20 & 13 & 39 \\
\hline Airtel & 7 & 7 & 3 & 17 \\
\hline Orange & 1 & 13 & 1 & 15 \\
\hline Total & 14 & 40 & 17 & 71 \\
\hline
\end{tabular}

Network Service Control and Feeder Cable

$\begin{array}{lllll}\text { Safaricom } & 10 & 22 & 7 & 39 \\ \text { Airtel } & 5 & 10 & 2 & 17 \\ \text { Orange } & 11 & 4 & 0 & 15 \\ \text { Total } & 26 & 36 & 9 & 71\end{array}$

Network Service Control and Node B

$\begin{array}{lllll}\text { Safaricom } & 1 & 17 & 21 & 39 \\ \text { Airtel } & 1 & 12 & 4 & 17 \\ \text { Orange } & 0 & 8 & 7 & 15 \\ \text { Total } & 2 & 37 & 32 & 71\end{array}$

Network Service Control and Transmission Equipment

\begin{tabular}{lllll} 
Safaricom & 0 & 35 & 4 & 39 \\
Airtel & 0 & 16 & 1 & 17 \\
Orange & 0 & 12 & 3 & 15 \\
Total & 0 & 63 & 8 & 71 \\
\hline
\end{tabular}

\section{Source: Research Data}

From the findings, a total of only 6 out of 39 respondents of Safaricom (15\%), 7 out of 17 respondents from Airtel (41\%) and only 1 out of 15 respondents from Orange $(6 \%)$ agreed that network service control was a hindrance to realization of sharing antennas in an open ICT infrastructure sharing framework by Mobile Service Providers in Kenya. 10 respondents from Safaricom (26\%), 5 respondents from Airtel(29\%) and 11 respondents from Orange $(73.3 \%)$ agreed that network service control had a major impact on realization of sharing feeder cables in an open ICT infrastructure sharing by Mobile Service Providers in Kenya. Only 1 respondent from Safaricom (3\%), only 1 respondent from Airtel $(6 \%)$ and none from Orange agreed that network service control had a major impact on realization of sharing feeder cables in an open ICT infrastructure sharing by Mobile Service Providers in Kenya. None of the respondents in all the three Mobile Service Providers agreed that network service control had a major impact on realization of sharing feeder cables in an open ICT infrastructure sharing by Mobile Service Providers in Kenya.

\section{Programme complexity and Risk}

In the survey, the respondents were asked to indicate whether they thought Programme Complexity had an impact to realization of Open ICT infrastructure sharing with respect to Antennae, Feeder cables, Node B and Transmission equipment. The table below illustrates the findings:
Table 8. Programme complexity

\begin{tabular}{|c|c|c|c|c|}
\hline \multicolumn{4}{|c|}{ Programme Complexity and Antennae } & \multirow[t]{2}{*}{ Total } \\
\hline & Yes & No & Not Sure & \\
\hline Safaricom & 22 & 8 & 9 & 39 \\
\hline Airtel & 11 & 2 & 4 & 17 \\
\hline \multirow[t]{2}{*}{ Orange } & 6 & 4 & 5 & 15 \\
\hline & 39 & 14 & 18 & 71 \\
\hline \multicolumn{5}{|c|}{ Programme Complexity and Feeder Cables } \\
\hline Safaricom & 19 & 1 & 19 & 39 \\
\hline Airtel & 7 & 1 & 9 & 17 \\
\hline Orange & 11 & 4 & 0 & 15 \\
\hline Total & 37 & 6 & 28 & 71 \\
\hline \multicolumn{5}{|c|}{ Programme Complexity and Node B } \\
\hline Safaricom & 39 & 0 & 0 & 39 \\
\hline Airtel & 11 & 0 & 6 & 17 \\
\hline Orange & 9 & 0 & 6 & 15 \\
\hline Total & 59 & 0 & 12 & 71 \\
\hline $\begin{array}{l}\text { Programme } \\
\text { Equipment }\end{array}$ & \multicolumn{2}{|c|}{ Complexity and } & Transmission & \\
\hline Safaricom & 19 & 19 & 1 & 39 \\
\hline Airtel & 7 & 6 & 4 & 17 \\
\hline Orange & 12 & 3 & 0 & 15 \\
\hline Total & 38 & 28 & 5 & 71 \\
\hline
\end{tabular}

Source: Research Data

From the table above, 22 respondents from Safaricom (56\%), 11 respondents from Airtel (65\%) and 6 respondents from Orange $(40 \%)$ agreed that programme complexity is a hindrance factor to the realization of sharing antennas in an open ICT infrastructure sharing framework by Mobile Service Providers in Kenya. With regards to feeder cables, 19 respondents from Safaricom (49\%), 7 respondents from Airtel (41\%) and 11 respondents from Orange $(73 \%)$ agreed that programme complexity is a hindrance factor to the realization of sharing feeder cables in an open ICT infrastructure sharing framework by Mobile Service Providers in Kenya. All the respondents from Safaricom (100\%), 11 respondents from Airtel (65\%) and 9 respondents from Orange $(60 \%)$ agreed that programme complexity is a hindrance factor to the realization of sharing Node B's in an open ICT infrastructure sharing framework by Mobile Service Providers in Kenya. 19 respondents from Safaricom (49\%), 7 respondents from Airtel (41\%) and 12 respondents from Orange $(80 \%)$ agreed that programme complexity is a hindrance factor to the realization of sharing transmission equipments in an open ICT infrastructure sharing framework by Mobile Service Providers in Kenya.

\section{Experience and Resources}

In the survey, the respondents were asked to indicate whether they thought Experience and Resources had an impact to realization of Open ICT infrastructure sharing with respect to Antennae, Feeder cables, Node B and Transmission equipment. The table below illustrates the findings: 
Table 9. Experience and Resources

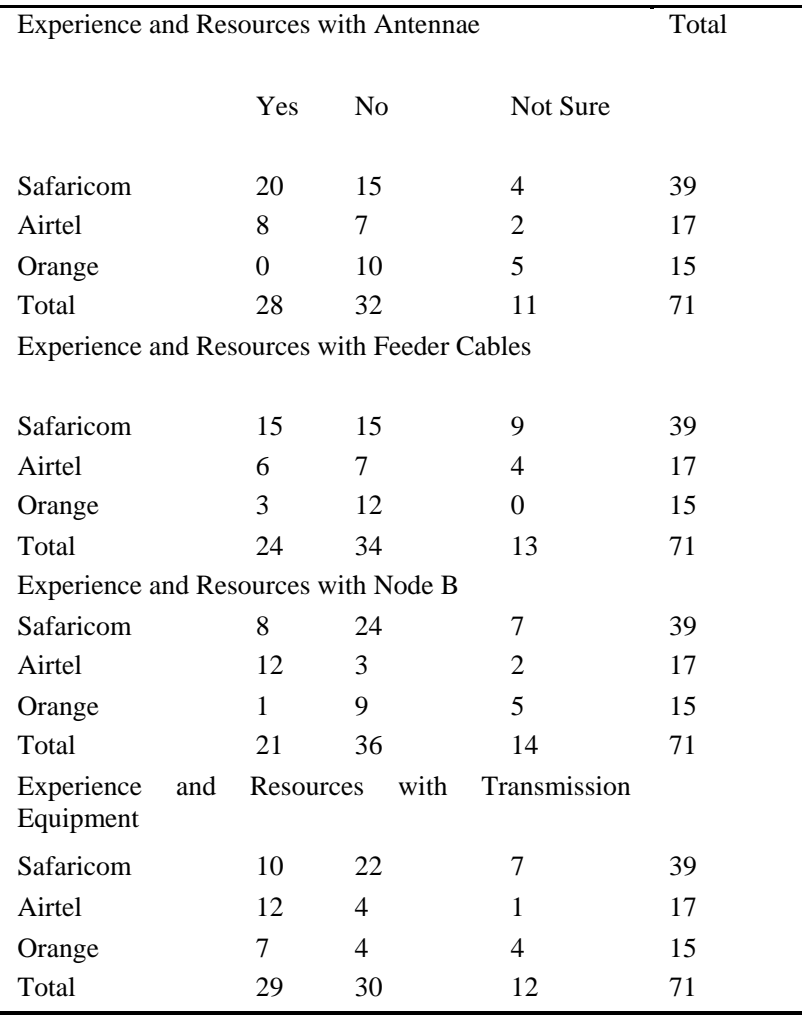

Source: Research Data

From the table above, 20 respondents from Safaricom $(51.2 \%), 8$ respondents from Airtel $(47 \%)$ and no respondents from Orange $(0 \%)$ agreed that experience with resources is a hindrance factor to the realization of sharing antennas in an open ICT infrastructure sharing framework by Mobile Service Providers in Kenya. 15 respondents from Safaricom (38\%), 6 respondents from Airtel (35\%) and only 3 respondents from Orange (20\%) agreed that experience with resources is a hindrance factor to the realization of sharing feeder cables in an open ICT infrastructure sharing framework by Mobile Service Providers in Kenya.

With regard to Node B's, 8 respondents from Safaricom (21\%), 12 respondents from Airtel (71\%) and only 1 respondent from Orange $(6 \%)$ agreed that experience with resources is a hindrance factor to the realization of sharing Node B's in an open ICT infrastructure sharing framework by Mobile Service Providers in Kenya. 10 respondents from Safaricom (26\%), 12 respondents from Airtel (71\%) and 7 respondents from Orange (48\%) agreed that experience with resources is a hindrance factor to the realization of sharing transmission equipment in an open ICT infrastructure sharing framework by Mobile Service Providers in Kenya.

\section{Hypothesis Testing}

The null hypothesis stated that there exists no relationship between networks sharing in each of the three Mobile Service Providers in against the alternative there exists relationship between networks sharing in each of the three Mobile Service Providers. With respect to Antennae, the table below illustrates the findings.

Table 10. Relationship between responses for Antennae in three Mobile Service Providers

\begin{tabular}{llll}
\hline & Value & df & $\begin{array}{l}\text { Asymp. Sig. } \\
(2 \text {-sided) }\end{array}$ \\
\hline Pearson Chi-Square & $7.608^{\mathrm{a}}$ & 8 & .473 \\
Likelihood Ratio & 10.429 & 8 & .236 \\
Linear-by-Linear & .027 & 1 & .869 \\
Association & & & \\
N of Valid Cases & 71 & & \\
\hline
\end{tabular}

Source: Research Data

From the results above, Pearson Chi-Square statistic, $\chi^{2}$ $=7.890$, and $p>0.001$; that is probability of the observed data under the null hypothesis is of relationship. The null hypothesis is accepted. It can be concluded that all the respondents in three Mobile Service Providers do not have similar views when it comes to sharing antenna in the context of open ICT infrastructure sharing by Mobile Service Providers in Kenya.

Table 11. Relationship between responses for Feeder Cables in three Mobile Service Providers

\begin{tabular}{llll}
\hline & Value & df & $\begin{array}{l}\text { Asymp. Sig. } \\
(2 \text {-sided) }\end{array}$ \\
\hline Pearson Chi-Square & $9.777^{\mathrm{a}}$ & 6 & .134 \\
Likelihood Ratio & 12.570 & 6 & .050 \\
Linear-by-Linear & 5.303 & 1 & .021 \\
Association & & & \\
N of Valid Cases & 71 & & \\
\hline
\end{tabular}

Source: Research Data

From the results above, Pearson Chi-Square statistic, $\chi^{2}$ $=9.777$, and $p>0.001$; that is probability of the observed data under the null hypothesis is of relationship. The null hypothesis is accepted. It can be concluded that all the respondents in three Mobile Service Providers do not have similar views when it comes to sharing feeder cables in the context of open ICT infrastructure sharing by Mobile Service Providers in Kenya.

Table 12. Relationship between responses for Node B in three Mobile Service Providers

\begin{tabular}{llll}
\hline & Value & df & $\begin{array}{l}\text { Asymp. Sig. } \\
(2 \text {-sided })\end{array}$ \\
\hline Pearson Chi-Square & $15.624^{\mathrm{a}}$ & 6 & .016 \\
Likelihood Ratio & 18.444 & 6 & .005 \\
Linear-by-Linear & .566 & 1 & .452 \\
Association & & & \\
N of Valid Cases & 71 & & \\
\hline
\end{tabular}

Source: Research Data

From the results above, Pearson Chi-Square statistic, $\chi^{2}$ $=7.387$, and $\mathrm{p}<0.05$; that is a very small probability of the observed data under the null hypothesis is of no relationship. The null hypothesis is rejected, since $\mathrm{p}<$ 0.05 . Hence the alternative hypothesis that there exists a 
relationship between Node B sharing in three Mobile Service Providers is accepted. It can be concluded that all the respondents in three Mobile Service Providers have similar views when it comes to sharing Node B's in the context of open ICT infrastructure sharing by Mobile Service Providers in Kenya.

Table 13. Relationship between responses for Transmission Equipment in three Mobile Service Providers

\begin{tabular}{llll}
\hline & Value & Df & $\begin{array}{l}\text { Asymp. Sig. } \\
\text { (2-sided) }\end{array}$ \\
\hline Pearson Chi-Square & $21.169^{\mathrm{a}}$ & 6 & .002 \\
Likelihood Ratio & 25.677 & 6 & .000 \\
Linear-by-Linear & 6.583 & 1 & .010 \\
Association & & & \\
N of Valid Cases & 71 & & \\
\hline
\end{tabular}

Source: Research Data

From the results above, Pearson Chi-Square statistic, $\chi^{2}$ $=21.169$, and $\mathrm{p}<0.05$; that is a very small probability of the observed data under the null hypothesis is of no relationship. The null hypothesis is rejected, since $\mathrm{p}<$ 0.05 . Hence the alternative hypothesis that there exists a relationship between transmission equipment sharing in three Mobile Service Providers is accepted. It can be concluded that all the respondents in three Mobile Service Providers have similar views when it comes to sharing transmission equipment in the context of open ICT infrastructure sharing by Mobile Service Providers in Kenya.

\section{E. Summary, Conclusions and Recommendations}

The study sought to investigate the effects of network infrastructure challenges on open ICT infrastructure sharing by Mobile Service Providers in Kenya. Specifically, the study investigated network sharing challenges as the main determinant of open ICT infrastructure sharing by Mobile Service Providers in Kenya. The empirical literature revealed that Open ICT Infrastructure sharing can substantially reduce capital and operational expenditure thereby increasing the speed of network rollouts, improve coverage and help meet the capacity demands of increased data traffic. Other reviews revealed that each sharing environment is different and may have pressures and priorities that change throughout the process of establishing a partnership between two operators. Network service control and Coverage, Network growth, Experience and Resources and Market Dynamics were identified as the main challenges facing Network sharing by Mobile Service Providers.

The findings of this study revealed that a majority of respondents from the three Mobile Service Providers did not agree that antennas, Node B's and transmission equipments could be shared in an open ICT infrastructure sharing framework. A fairly average majority of respondents agreed that feeder cables could be shared in an open ICT infrastructure sharing framework. Network service coverage and control, programme complexity and risk and experience and resources were found to have a profound effect on open ICT infrastructure sharing by Mobile Service Providers in Kenya. Programme complexity and risk was found to have a major impact on open ICT infrastructure sharing by Mobile Service Providers in Kenya. This study also found out that there is no relationship between networks sharing in each of the three Mobile Service Providers in Kenya from the hypothesis tested using Pearson's chi-square. The output of this study indicated that antennas, Node B and transmission equipments are difficult to share in an open ICT infrastructure sharing framework. Programme complexity was identified as the main hindrance to realization of sharing these components. The study is a justification of the fact Mobile Service Providers' interest in Open ICT infrastructure sharing is alive due since open ICT Infrastructure sharing can substantially reduce capital and operational expenditure thereby increasing the speed of network rollouts, improving coverage and helping to meet the capacity demands of increased data traffic. However network sharing challenges such as network service control and coverage, network growth, Experience and Resources and Market Dynamics hinder the realization of open ICT infrastructure sharing by Mobile Service Providers in Kenya.

Specifically, this study recommends:

i. A neutral body or company should be formed by Mobile Service Providers to manage the ICT infrastructure such as steel towers, BTS shelters, power supply, generators and feeder cables on behalf of the Mobile Service Providers. The company will be in charge of carrying out asset valuation and managing the ICT infrastructure on behalf of the Mobile Service Providers.

ii. The Communications Authority of Kenya should formulate a legislation that defines clear rules and guidelines on open ICT infrastructure sharing by Mobile Service Providers in Kenya. Such rules will guide new entrants and incumbents in embracing open ICT infrastructure sharing by Mobile Service Providers in Kenya.

iii. For successful implementation of open ICT infrastructure sharing framework by Mobile Service Providers in Kenya, the components to be shared should be restricted to only BTS shelters, steel towers, power supply, generators, batteries (site sharing components) and feeder cables (network sharing component). The other components such as antennas, Node B's and transmission equipments should be left to each Mobile Service Providers so that each Mobile Service Provider can differentiate its service to its clients.

\section{Recommendations for Further Research}

This study is a milestone for future research in this area, particularly in Kenya. The findings emphasize the effects of site sharing challenges, network sharing challenges, radio spectrum challenges and regulatory challenges on open ICT infrastructure sharing by Mobile Service Providers in Kenya. However, the study focussed only on the $2 \mathrm{G}$ and $3 \mathrm{G}$ network technologies without considering $4 \mathrm{G}$ networks, since no Mobile Service Provider in Kenya 
had migrated to $4 \mathrm{G}$ at the time of conducting this study. As a result, results obtained may not be representative of the entire Mobile Service Industry across the globe. Further research should be conducted in this area.

\section{REFERENCES}

[1] Z. Isamuyo, "OPEN ACCESS ICT INFRASTRUCTURE IN RURAL TANZANIA TECHNOLOGY, DESIGN, AND POLICY," Royal Institute of Technology Stockholm, Sweden, Stockholm, 2006.

[2] Y. Punie, "Learning Spaces: An ICT-Enabled Model of Future Learning in the Knowledge-Based Society," European Journal of Education, vol. 42, no. 2, pp. 185199, Jun. 2007.

[3] L. Bauer, M. Westerveld, and D. Maitland, "Value Network of Mobile Content Providers," 2, vol. V1-205, p. 15, Jul. 2001

[4] K. Zahra, P. Azim, and A. Mahmood, "Telecommunication Infrastructure Development and Economic Growth: A Panel Data Approach," The Pakistan Development Review, vol. 47, no. 4, pp. 711-726, Dec. 2008.

[5] Sony Ericsson, "A structured approach to network sharing- how to benefit while maintaining competitive advantage," Sony Ericsson, Europe, 286 23-3144, Sep. 2010.

[6] P. A. Valberg, T. E. van Deventer, and M. H. Repacholi, "Workgroup Report: Base Stations and Wireless Networks: Radiofrequency (RF) Exposures and Health Consequences," Environmental Health Perspectives, vol. 115, no. 3, pp. 416-424, Mar. 2007.

[7] C. Lefervre, "Mobile Sharing. 8th Global Symposium for Regulators." Aug. 2009.

[8] CCK, NETWORK FACILITIES PROVIDER TIER 1 LICENCE. 2004, p. 20.

[9] A. Mahmood, "Fiber Optic sharing in Kenya." Oxford University Press, May-2012.

[10] Republic of Kenya, "Kenya Vision 2030,” Aug. 2007.

[11] Yousaf Haroon Mujahid and S. R. Siddiqui, "Digital Opportunity Initiative for Pakistan [with Comments]," The Pakistan Development Review, vol. 40, no. 4, pp. 911-928, Dec. 2001.

[12] J. Barney, "Firm resources and sustained competitive advantage," Journal of Management, vol. 3, p. 103, 1991.

[13] C. Hauert and G. Szabó, "Game theory and physics," American Journal of Physics, vol. 73, p. 405, 2005.

[14] D. G. Alemneh and S. K. Hastings, "Developing the ICT Infrastructure for Africa: Overview of Barriers to Harnessing the Full Power of the Internet," Journal of Education for Library and Information Science, vol. 47, no. 1, pp. 4-16, Jan. 2006.

[15] I. Chatzicharistou, "Infrastructure Sharing in Mobile Service Market: Investigating the final decisions of the network operators," Delft University of Technology, Delft University of Technology, 2010.

[16] PTA, "CONSULTATION PAPER ON INFRASTRUCTURE SHARING OF CELLULAR MOBILE COMPANIES,” PTA, Islamabad, Aug. 2007.

[17] DANU, "Shared Networks - Performance Management Challenges," DANU, DANU, 2012.

[18] T. Saphyre, Sharing Physical Resources- Mechanisms and Implementations for Wireless Networks, 3rd ed. Europe: SAPHYRE, 2010.

[19] S. White, R. Shetty, J. Santos, and C. Woodland, "Passive Infrastructure Sharing in Telecommunications." KPMG.COM, 2011.
[20] T. Levine, P. Eijsvoogel, and M. Reede, "Passive Infrastructure Sharing.” ALLEN \& OVERY, 2012.

[21] CCK, "ANALYSIS OF 2010 ICT SURVEY." CCK, Dec2010.

[22] KNBS, "Employment Statistics," KNBS, Nairobi, May 2012.

[23] C.-W. Tsai and P.-D. Shen, "Applying web-enabled selfregulated learning and problem-based learning with initiation to involve low-achieving students in learning," Computers in Human Behaviour, vol. 25, no. 6, pp. 1189 1194, 2009.

[24] S. J. Paxton, S. A. McLean, E. K. Gollings, C. Faulkner, and E. H. Wertheim, "Comparison of face-to-face and internet interventions for body image and eating problems in adult women: An RCT," International Journal of Eating Disorders, vol. 40, no. 8, pp. 692-704, 2007.

[25] M. V. Magagane, "Infrastructure sharing and access to broadband: the role of policy and regulation," University of Witwatersrand, 2012.

\section{Authors' Profile}

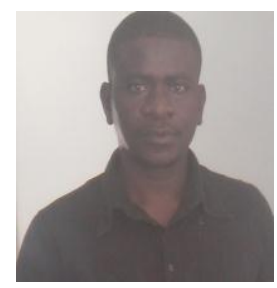

Mr. Peter Namisiko Wanjala is a Post Graduate Student and a Researcher at Jomo Kenyatta University of Agriculture and Technology. He holds a Bachelor Science Degree (Hons) in Computer Science from Egerton University, Kenya and a Master of Science Degree in Telecommunications from California Miramar University, San Diego, California. His current research interests are Telecommunications Management, ICT Policy, ICT4D, E-Learning Systems and Next Generations Networks.

Dr. Maurice Sakwa holds a Bachelor of Education Degree from Kenyatta University (Kenya), Oxford Special Diploma in Social Sciences (Oxford, UK), and Master of Science Degree from University of East Anglia (UK) and Doctorate Degree from Radbound University Nijmegen (Netherlands). He is currently a Senior Lecturer, Department of Social Sciences and Humanities, College of Human Resource Development at Jomo Kenyatta University of Agriculture and Technology (JKUAT), Kenya. Dr. Sakwa has co-authored several journal articles in the areas of development, Business, ICT and society. He has also authored a book in the area of development. His academic research interests spans technology and development, ICT and society, development economics among others.

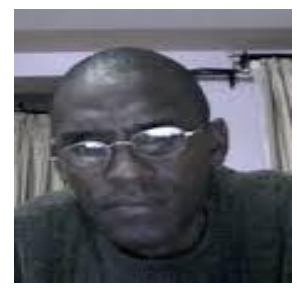

Prof. Waweru Mwangi holds Bachelor of Science Degree in Mathematics from Kenyatta University (Kenya), a Master of Science Degree in Operation Research from Shanghai University (China) and $\mathrm{PhD}$ in Systems and Information Engineering from Hokkaido University (Japan). He is currently an Associate Professor in the Department of Computing, School of Computing and Informatics at JKUAT. His research areas include; systems modelling and development, smart agent computing, simulation and ICT policy formulation

Manuscript received November 14, 2014; revised January 14 , 2015; accepted January 27, 2015. 